\title{
Analysis of child victims of trauma or violence reported for medico- legal examination in three tertiary care hospitals in Sri Lanka
}

Kitulwatte IDG ${ }^{1 *}$, Edirisinghe PAS, Appuhamy $\mathrm{P}^{2}$

${ }^{1}$ Department of Forensic Medicine, Faculty of Medicine, Ragama, ${ }^{2}$ Institute of Legal Medicine and Toxicology, Colombo

*Corresponding author: Tel: 0094-71-961237. E-mail address: indiradgk@yahoo.com

MLJSL. Vol 1. No 2. Aug. pp 28 - 36

\section{Abstract}

\section{Introduction}

Injury is a leading cause of disability among children and young adults. Characteristics of child victims of trauma or violence presenting for medico legal examination may vary considerably by age, sex and developmental level of the child.

Objective: The primary objective of this study was to find out type, distribution and severity of trauma or violence among children presenting for medico legal examination. The second aim was to propose suggestions to prevent such trauma or violence to children.

Study Design: Retrospective descriptive study was done based on medico-legal examinations performed on all the children under 12 years by the authors. The information was gathered on a proforma to fulfill the objectives. The data was analyzed using SPSS statistical package.

Results: Out of 171 cases studied 54\% of cases were alleged road traffic accidents, alleged nonaccidental injuries $16 \%$ and alleged sexual abuse $12 \%$. Sexual violence was commonly seen among female victims (75\%). The age of the sexual abuse victims ranged from 1 year to 12 years. $60 \%$ of victims of alleged physical abuse were more than 10 years of age. $56 \%$ of accidental injuries and $80 \%$ of non-accidental injuries were non grievous. Head injuries amounted to $68 \%$ of accidental injuries while commonest non accidental injuries were also found on the head and neck (53\%).

Conclusion: Although road accidents are the commonest trauma among children presenting for medico legal examination, there is a significant proportion of intentional trauma including sexual violence. Thus, the preventive strategies should aim on both accidental and non accidental trauma.

Key words: child victims, trauma or violence, accidents, physical abuse, sexual violence

\section{Introduction}

Hospitalized child victims referred for medico legal examination include both victims of physical violence as well as sexual violence. The literature on traumatic or physical injuries of children includes both accidental injuries and non accidental or violence related injuries. The incidence of traumatic injuries in children is on the increase worldwide. [1] Children could be 
the first to face interpersonal violence and feel the burden in almost any country since they are the most vulnerable groups in society. [2] In recent years a great deal of public and media attention has been paid to child victims of abuse. Violence-related injury is a leading cause of child mortality, morbidity and disability especially in lowincome countries. [3] Among them accidents remain the leading cause of death, serious morbidity, and permanent disability in a number of countries. [4] On the other hand, the problem of sexual violence in children has been underaddressed due to the culture of silence specific to it and the victims being uncomfortable during court proceedings. Overall victimization of children due to accidental, non accidental and sexual trauma needs proper attention to design programmes targeted at children at risk to prevent and control child victimization of violence. Characteristics of child victims of trauma or violence presenting for medico legal examination may vary considerably by age, sex and developmental level of the child. This study was planned to outline the features of hospitalized child victims from a medico-legal perspective.

\section{Objective:}

The primary objective of this study was to find out the type, distribution and severity of trauma or violence among children presenting for medico legal examination. The second aim was to propose suggestions to prevent such trauma or violence to children.

\section{Method:}

A retrospective descriptive study was carried out on children less than 12 years hospitalized in tertiary care hospitals where medico legal examination forms had been issued. The study was done based on historical and examination documentations of medico-legal examinations carried out by the authors on hospitalized children less than 12 years of age. The information was gathered on a proforma to fulfill the objectives. The data was analyzed using SPSS statistical package.

\section{Results:}

Out of 171 children admitted n-121 (71\%) children were between 5 to 12 years. 26 $(15 \%)$ children were between 3 to 5 years. There were 19 (11\%) children of 1 to 3 years of age and 5 (3\%) children less than 1 year. (Table 1)

Majority n-94 (55\%) presented after road traffic accidents(RTA). There were 29 (17\%) cases of alleged intentional trauma while 21 (12 \%) cases were alleged sexual abuse. Among the others there were alleged violence caused by peers, accidental falls and poisoning.

Out of 94 road accident cases 66 (70\%) were of 5 to 12 years of age while there were $16(17 \%)$ children of $3-5$ years of age and $9(10 \%)$ of 1 to 3 year age. Majority of victims of intentional trauma $n-23$ (79\%) were of 5 to 12 years of age. (Table 1 )

Alleged sexual abuse was observed among children of all ages. Out of 21 cases of alleged sexual abuse 15 (71\%) were of the age group of $5-12$ years while there were 3 children each among the victims of alleged sexual abuse in the age groups of 3 to 5 years and $1-3$ years. (Table 1 ) 
Table: 1 age distribution in relation to the presentation

\begin{tabular}{|c|c|c|c|c|c|c|c|c|c|c|}
\hline \multirow{2}{*}{\begin{tabular}{|r} 
Age \\
$<1$ ry
\end{tabular}} & \multicolumn{2}{|c|}{ RTA } & \multicolumn{2}{|c|}{ intentional trauma } & \multicolumn{2}{|c|}{ sexual abuse } & \multicolumn{2}{|c|}{ other } & \multicolumn{2}{|c|}{ Total } \\
\hline & 3 & $3 \%$ & 1 & $3.5 \%$ & 0 & $0 \%$ & 1 & $4 \%$ & 5 & $3 \%$ \\
\hline $1-3 y r s$ & 9 & $10 \%$ & 1 & $3.5 \%$ & 3 & $14.5 \%$ & 6 & $22 \%$ & 19 & $11 \%$ \\
\hline 3-5yrs & 16 & $17 \%$ & 4 & $14 \%$ & 3 & $14.5 \%$ & 3 & $11 \%$ & 26 & $15 \%$ \\
\hline 5-12yrs & 66 & $70 \%$ & 23 & $79 \%$ & 15 & $71 \%$ & 17 & $63 \%$ & 121 & $71 \%$ \\
\hline Total & 94 & $100 \%$ & 29 & $100 \%$ & 21 & $100 \%$ & 27 & $100 \%$ & 171 & $100 \%$ \\
\hline
\end{tabular}

Non grievous category was predominant among the overall study group $\mathrm{n}-112$ (65\%). However there were 45 (26\%) grievous, 3 (2\%) endangering life and $1(1 \%)$ fatal in the ordinary course of nature injuries among the victims. $54(58 \%)$ of the road traffic accident injuries were non grievous while there were $38(40 \%)$ grievous injuries. Out of 29 victims of intentional trauma $23(79 \%)$ were having non grievous injuries while 4 (14\%) had grievous and $2(7 \%)$ had injuries endangering life. $16(76 \%)$ out of 21 victims of sexual abuse were having associated non grievous injuries. (Table 2)

Table : 2 Category of hurt in relations to presentation

\begin{tabular}{|c|c|c|c|c|c|c|c|c|c|c|}
\hline \multirow{2}{*}{$\begin{array}{c}\text { Category } \\
\text { non grievous }\end{array}$} & \multicolumn{2}{|c|}{ RTA } & \multicolumn{2}{|c|}{ intentional trauma } & \multicolumn{2}{|c|}{ sexual abuse } & \multicolumn{2}{|c|}{ Other } & \multicolumn{2}{|c|}{ Total } \\
\hline & 54 & $58 \%$ & 23 & $79 \%$ & 16 & $76 \%$ & 19 & $70 \%$ & 112 & $65 \%$ \\
\hline grievous & 38 & $40 \%$ & 4 & $14 \%$ & 0 & $0 \%$ & 3 & $11 \%$ & 45 & $26 \%$ \\
\hline endangering life & 1 & $1 \%$ & 2 & $7 \%$ & 0 & $0 \%$ & 0 & $0 \%$ & 3 & $2 \%$ \\
\hline FIOCN & 1 & $1 \%$ & 0 & $0 \%$ & 0 & $0 \%$ & 0 & $0 \%$ & 1 & $1 \%$ \\
\hline Not applicable & 0 & $0 \%$ & 0 & $0 \%$ & 5 & $24 \%$ & 5 & $19 \%$ & 10 & $6 \%$ \\
\hline Total & 94 & $100 \%$ & 29 & $100 \%$ & 21 & $100 \%$ & 27 & $100 \%$ & 171 & $100 \%$ \\
\hline
\end{tabular}

There were $98(57 \%)$ males and $73(43 \%)$ females among the study group. Males were predominant among the victims of road accidents as well as among the intentional trauma group. However females were the mostly affected victims of sexual abuse 16 (76\%) compared to 5 (24\%) males. (Table: 3 ) 


\begin{tabular}{c|c|c|c|c|c|c|c|c|c|c|}
\hline & \multicolumn{2}{|c|}{ RTA } & \multicolumn{2}{c|}{ intentional trauma } & \multicolumn{2}{c|}{ sexual abuse } & \multicolumn{2}{|c|}{ Other } & \multicolumn{3}{c|}{ Total } \\
\hline male & 57 & $61 \%$ & 24 & $83 \%$ & 5 & $24 \%$ & 12 & $63 \%$ & 98 & $57 \%$ \\
female & 37 & $39 \%$ & 5 & $17 \%$ & 16 & $76 \%$ & 7 & $37 \%$ & 73 & $43 \%$ \\
Total & 94 & $100 \%$ & 29 & $100 \%$ & 21 & $100 \%$ & 27 & $100 \%$ & 171 & $100 \%$ \\
\hline
\end{tabular}

Table 3: sex distribution according to the presentation

Among the total group, injuries were found on multiple sites in majority $n-59$ (35\%) of the cases. There were $43(25 \%)$ isolated head injuries and $22(13 \%)$ isolated injuries to extremities. Victims of road trauma were found to have injuries of multiple sites mainly $n-42$ (45\%) followed by isolated head injuries. However isolated head injuries were seen predominantly among the victims of intentional trauma. (Table 4)

Table 4: site of injury according to the presentation

\begin{tabular}{|l|l|l|l|l|l|l|}
\hline & \multicolumn{3}{|l}{ Overall } & \multicolumn{2}{l}{ RTA } & \multicolumn{2}{l|}{ Intentional trauma } \\
\hline Abrasions & 87 & $51 \%$ & 60 & $64 \%$ & 10 & $34 \%$ \\
\hline Contusions & 58 & $34 \%$ & 39 & $41 \%$ & 11 & $40 \%$ \\
\hline Lacerations & 43 & $25 \%$ & 31 & $33 \%$ & 3 & $10 \%$ \\
\hline Fracture & 41 & $24 \%$ & 31 & $33 \%$ & 0 & $0 \%$ \\
\hline Sharp force & 4 & $2 \%$ & 0 & $0 \%$ & 1 & $3 \%$ \\
\hline Burn & 6 & $3.5 \%$ & 1 & $1 \%$ & 1 & $3 \%$ \\
\hline Other & 7 & $4 \%$ & 3 & $3 \%$ & 2 & $7 \%$ \\
\hline
\end{tabular}

Abrasions were the commonest injury found. Out of 171 children 87 (51\%) were having abrasions either as an isolated injury or together with other injuries. Contusions were next in line and there were 58 (34\%) children among the study group with contusions. There were $43(25 \%)$ children with lacerations and $41(24 \%)$ with fractures. Out of 171 children, there were 4 (2\%) cases of sharp force trauma and 6 (3.5\%) burns. (Table 5)

Table 5: type of injury in road accidents and intentional trauma

\begin{tabular}{|l|c|c|c|c|c|c|c|c|c|c|}
\hline & \multicolumn{2}{|c|}{ RTA } & \multicolumn{2}{c|}{ Other } & \multicolumn{2}{c|}{ intentional trauma } & \multicolumn{2}{c|}{ sexual abuse } & \multicolumn{2}{c|}{ Total } \\
\hline Torso & 6 & $6 \%$ & 2 & $7 \%$ & 1 & $3 \%$ & 0 & $0 \%$ & 9 & $5 \%$ \\
\hline Extremities & 12 & $13 \%$ & 6 & $22 \%$ & 4 & $14 \%$ & 0 & $0 \%$ & 22 & $13 \%$ \\
\hline Multiple & 42 & $45 \%$ & 8 & $30 \%$ & 8 & $28 \%$ & 1 & $5 \%$ & 59 & $35 \%$ \\
\hline Head & 27 & $29 \%$ & 5 & $19 \%$ & 11 & $38 \%$ & 0 & $0 \%$ & 43 & $25 \%$ \\
\hline Other & 7 & $7 \%$ & 6 & $22 \%$ & 5 & $17 \%$ & 20 & $95 \%$ & 38 & $22 \%$ \\
\hline Total & 94 & $100 \%$ & 27 & $100 \%$ & 29 & $100 \%$ & 21 & $100 \%$ & 171 & $100 \%$ \\
\hline
\end{tabular}


Among the 94 victims of road trauma there were 60 (64\%) children with abrasions. Contusions were again the second in line which was seen in 39 (41\%). There were 31 (33\%) lacerations and fractures each. (Table 5)

Commonest injury in intentional trauma was contusions $n-11(40 \%)$ followed by abrasions which were seen in 10 (34\%) out of 29 children. There were $3(10 \%)$ children with lacerations and 1 (3\%) child each with sharp force trauma and burn. (Table 5)

\section{Discussion:}

The application of forensic medicine is not only limited to the administration of justice. It is being used more and more to address public health and safety issues especially in the prevention of trauma or violence.

It is a responsibility of the forensic expert to provide continuity of care from trauma to trial. Proper understanding of the existing problems is extremely important in fulfilling this task.

The study revealed that $71 \%$ hospitalized children referred for medico-legal examination is of the age group of 5-12 years. Furthermore, there was a gradual rise of number of victims referred for medico legal examination from infancy to pre-school age. This pattern had been observed in a large scale retrospective study conducted in Israel on violence related injuries. [5] In our study, majority of children $55 \%$ were victims of road traffic accidents. There were $17 \%$ victims of alleged intentional trauma while $12 \%$ cases were alleged sexual abuse victims. Though road accidents remain the major cause for medico-legal referral among this age group both intentional physical violence and sexual violence are on the rise. Non intentional trauma has been identified as a major reason for injuries among children of 6 to 12 years [6] while intentional violence was identified as the major reason for injuries among older children and adolescents indicating that they are a distinct target group when considering how to deal with the problem of violence[5]. Similarly, incidence of sexual abuse increases with age. [7] The children of 5-12 years in our study are mainly victims of non intentional trauma though there is a significant rise in intentional violence and sexual violence which is expected to be the main cause for injury in the next age group, adolescents.

Though alleged sexual abuse cases were observed among children of all ages $71 \%$ of the cases were of 5 to 12 years of age. It has been reported that common victims of child sexual abuse are 10 years of age or younger. However, in the same study it is highlighted that more than the chronological age sexual maturity with Tanner staging is important in classifying commonly affected victims. [8]

Non grievous category was seen among $65 \%$ of the overall study group, while $58 \%$ of the road traffic accident victims and $79 \%$ of the intentional trauma victims were having non grievous injuries. Injuries of child abuse are commonly non serious while only $2 \%$ severe cases and $4 \%$ fatalities have been reported in a study done in Uganda. [9] However there were $26 \%$ of grievous injuries among the study group which had been mainly contributed by road trauma. Road accidents in Sri Lanka are generally on the rise and it is more so for the children as well. [10].In a Sri Lankan 
study, on statistics of accidents approximately $10 \%$ of grievous injuries and $5 \%$ of fatalities were found among the cases of reported accidents in 2005 [10]. However in our study, among the child victims of road accidents there were $40 \%$ of grievous injuries. The study did not consider the fatalities and we have only included the hospitalized victims in a tertiary care setting.

The study revealed that the males were predominating as the victims of overall group (57\%) as well as the group of intentional trauma (83\%) and road accidents (61\%). However females were the main victims of sexual violence (76\%). Male predominance in accidental and intentional physical violence has been described in other studies. $[5,11,12]$. Females were commonly victimized in sexual violence. It has been reported that girls are at a higher risk of been victimized in child sexual violence than males. $[13,14]$ However, community studies on young persons in Sri Lanka have revealed that males were more sexually abused than females when they were children indicating the depth of the iceberg phenomenon described in child abuse. $[15,16]$

Majority of the study group were having injuries on multiple sites and the same was true for the victims of road accidents. However isolated head injuries were found commonly in the victims of intentional trauma. Inflicted head injury is the most common cause of lethal child abuse. [17] In the Ugandan study, intentional injuries among the youth victims were found commonly on head, neck, and face. [9] Recently, it has been reported that nonaccidental injuries account for nearly $25 \%$ of all head-injured children under the age of 2 years admitted to hospital. [18]
The study revealed that blunt force trauma was the main mechanism of causation of injuries in child victims referred for medico legal examination. Majority were abrasions. There were abrasions in $51 \%$ of the total study population and $64 \%$ of the road trauma group. However contusions were seen commonly among the victims of intentional trauma. Bruising is one of the earliest, most common, and easily recognizable signs of physical child abuse. [19]

\section{Limitations of the study}

The study sample included hospitalized children with trauma and violence referred for medico legal examination in 3 tertiary care hospitals. Further, the sample is not a cross sectional sample. Therefore the true picture of the country at a given time may not be indicated here.

\section{Conclusions and recommendations}

In conclusion, there is a marked rise in victimization of children to trauma and violance at 5 to 12 years of age. Road accidents, intentional violence and sexual abuse are the main presentations of these children. Among them road accidents are the leading cause to report these children for medico legal examination. Boys are at a higher risk for road accidents and intentional violence while girls are at a higher risk for sexual abuse. Every day, children encounter a number of potential hazards. While it may be impossible to eliminate all dangers most are preventable. Many of these can be avaoided if necessary precautions are taken. Characterizing the patterns of childhood injury and identifying high risk groups are important in planning 
programmes targeted at preventing them. Parents and caregivers need to be educated about the greatest risk factors for their children and to take the appropriate steps to reduce the risk of unintentional injury. We propose that an educational package delivered by midwives and health visitors and school teachers can be effective in reducing such hazards. We further suggest that the health care professionals should take the lead in educating responsible teams. Future studies should be focused on prevention efforts for these childhood hazards. Furthermore, efforts should be focused towards making the legal system more child-victim friendly in order to minimize further trauma during this process.

\section{References}

1. Maria HP, Kurt DN, Martin RE et al. Patterns of injury in children. Journal of pediatric surgery 1990; 25(1): 85-91.

2. Sivarajasingam V, Moore S, Shepherd J. Violence in England and Wales 2006: an accident and emergency perspective. Available from: http://www.cardiff.ac.uk/dentl/resources/T rends_violence_England_Wales_2006.pdf [accessed 23 February 2009].

3. World report on violence and health. Geneva: World Health Organization; 2002.

4. Centers for Disease Control. Injury control in the 1990s: a national plan for action. Atlanta: Centers for Disease Control and Prevention, 1993.

5. Michael Rozenfeld \& Kobi Peleg, Violencerelated injury of children in Israel: agedependent pattern, Bull World Health Organ, 2009;87:362-368

6. Tanuj Kanchan, Ritesh G. Menezes, and Francis N.P. Monteiro, Fatal unintentional injuries among young children - A hospital based retrospective analysis, Journal of
Forensic and Legal Medicine, Volume 16, Issue 6, August 2009, Pages 307-311

7. Allan R. De Jong, Arturo R. Hervada, and Gary A. Emmett, Epidemiologic variations in childhood sexual abuse, Child Abuse \& Neglect, Volume 7, Issue 2, 1983, Pages 155-162

8. R. Lang, A.C. Rouget and V. van Santen, The Role of Victim Age and Sexual Maturity in Child Sexual Abuse, Sex Abuse October 1988 vol. 1 no. 4 467-484

9. Milton Mutto,Ronald Lett, Stephen Lawoko, Catherine Nansamba, Leif Svanstrom, Intentional injuries among Ugandan youth: a trauma registry analysis, Inj Prev 2010;16:333-336.

10. A.K. Somasundaraswaran, Accident statistics in Sri Lanka, latss Research Vol.30 No.1, 2006, 115-117

11. Donald William Spady, Duncan Leslie Saunders, Donald Peter Schopflocher, and Lawrence Walter Svenson, Patterns of Injury in Children: A Population-Based Approach, PEDIATRICS, Vol. 113 No. 3 March 2004, 522-529,

12. Rosa Gofin, Malka Avitzour, Ziona Haklai, and Navah Jellin, Intentional injuries among the young: presentation to emergency rooms, hospitalization, and death in Israel , Journal of Adolescent Health Volume 27, Issue 6, December 2000, Pages 434-442

13. R. Lang, A.C. Rouget and V. van Santen, The Role of Victim Age and Sexual Maturity in Child Sexual Abuse, Sex Abuse October 1988 vol. 1 no. 4 467-484, A. J., Broadhurst, D. D, Executive Summary of the Third National Incidence Study of Child Abuse and Neglect, 1996

14. M.B. Anthony W. Baker !' Sylvia P. Duncan, Child sexual abuse: A study of prevalence in Great Britain, Child Abuse \& Neglect, Volume 9, Issue 4, 1985, Pages 457-467 
15. De Silva DGH, Child abuse : The gravity of the problem \& Dilemmas in management in Sri Lanka. Published by unicef- Sri Lanka 1996

16. Fernando $A D$, Karunasekera, J. Juvenile victimisation in a group of young Sri Lankan adults. CMJ:2009:54:80-84

17. Cindy Christian, V Jordan Greenbaum, Epidemiology, mechanisms, and types of abusive head injury in infants and children, www.uptodate.com/patients/content/topic .do?.

18. Duhaime AC, Alario AJ, Lewander WJ, Schut L, Sutton LN, Seidl TS, et al. Head injury in very young children: mechanisms, injury types, and ophthalmologic findings in 100 hospitalized patients younger than 2 years of age. Pediatrics 1992; 90: 179-85.
19. Kim Kaczor, Mary Clyde Pierce, Kathi Makoroff and Tracey S. Corey, Bruising and Physical Child Abuse, Clinical Pediatric Emergency Medicine, Volume 7, Issue 3, September 2006, Pages 153160.

\section{Contribution of authors}

Design to the study - IDGK, PASE, PA

Supervision to the study- IDGK

Analysis of the data- IDGK, PA

Interpretation of the results- IDGK, PASE

Writing the manuscript -IDGK

Revising the manuscript-IDGK, PASE 